\title{
Proliferative Brenner Tumor with Borderline Mucinous Cystadenocarcinoma of the Ovary in a 75-Year-Old Woman
}

\author{
Kenji Niwa ${ }^{1}$, Hiroshi Makino ${ }^{2}$, Yoshio Yamaguchi ${ }^{3}$, Sakae Mori ${ }^{3}$, Nozomi Narikawa ${ }^{1}$, \\ Takuji Tanaka4 \\ ${ }^{1}$ Department of Obstetrics \& Gynecology, Gujo City Hospital, Gujo, Japan \\ ${ }^{2}$ Department of Obstetrics \& Gynecology, Gifu University Post-Graduate School of Medicine, Gifu, Japan \\ ${ }^{3}$ Section of Laboratory Medicine, Gujo City Hospital, Gujo, Japan \\ ${ }^{4}$ Department of Diagnostic Pathology (DDP) \& Research Center of Diagnostic Pathology (RC-DiP), Gifu \\ Municipal Hospital, Gifu, Japan \\ Email: kniwa.gujo913@gmail.com
}

Received 29 December 2013; revised 25 January 2014; accepted 5 February 2014

Copyright (C) 2014 by authors and Scientific Research Publishing Inc.

This work is licensed under the Creative Commons Attribution International License (CC BY).

http://creativecommons.org/licenses/by/4.0/

(c) $\underset{\mathrm{EY}}{\mathrm{B}}$ Open Access

\begin{abstract}
We report here an extremely rare case of proliferative Brenner tumor with borderline mucinous cystadenocarcinoma of the ovary, metastasizing to the pleura in a 75-year-old woman. Massive pleural effusion were present due to metastasis and pseudo-Meigs' syndrome. The cytological findings from pleural effusion, ascites and tumor imprint were similar, suggesting mucus-producing malignant tumors. After receiving a thoracic drainage for pleural effusion, the patient underwent an exploratory laparotomy to remove the left-ovarian tumor. Histopathological examination revealed proliferative Brenner ovarian tumor with borderline mucinous cystadenocarcinoma, and immunohistochemical examinations for the tumors, even mucus-rich tumor cells were positive for CK 7 and negative for CK 20, suggesting the tumor arising from transitional cells, not from mucus-producing ovarian surface epithelial tumor cells. She underwent four courses of chemotherapy with paclitaxel and carboplatin. The patient showed no signs of recurrence 16 months after the surgery.
\end{abstract}

\section{Keywords}

Proliferative Brenner Tumor, Ovary, Pseudo-Meigs' Syndrome, Transitional Cell, Cytology, Immunohistochemistry

\footnotetext{
${ }^{*}$ Corresponding author.
} 


\section{Introduction}

Brenner tumors (BTs) of the ovary are rare epithelial tumors that account for $1 \%$ - $2 \%$ of all ovarian neoplasms. Proliferative BT of the ovary was first described in 1971 by Roth and Sternberg [1], and was confirmed by Miles and Norris [2].

The terms of borderline malignancy and proliferating in reference to BTs were equated in the WHO publication [3]. It is a separate category of BT, being intermediate in its histologic appearance and biological aggressiveness compared with benign and malignant types of BTs [2][4][5]. There is a general agreement that BTs are derived from the surface epithelium of the ovary which has the properties of coelemic epithelium, and therefore, it undergoes metaplastic change to transitional or urothelial-like morphology [6]. We present here an extremely rare case of proliferative BT with borderline mucinous cystadenocarcinoma of the ovary in a 75-year-old woman, in which immunohistochemistry of CK 7 and CK 20 was useful for the diagnosis.

\section{Clinical Case}

A 75-year-old Japanese woman, gravida 0, visited our hospital complaining of dyspnea with abdomen distension. She had undergone an abdominal hysterectomy and rt-salpingo-oophorectomy due to leiomyoma and rt-ovarian benign cystic tumor at the age of 40-year-old. She had a mild senile dementia. Thus, she might not notice the abdominal distension. The detailed examination with CT revealed right-massive pleural effusion (Figure 1) and no other tumors except for pelvic mass were detected. She inserted a thoracic trocar tube due to dyspnea before surgery. The detailed examination with MRI showed a $10 \times 8 \mathrm{~cm}$, combined with solid and cystic parts (Figure 2). In a solid area, small cysts were frequently seen. Diffusion-weighted MRI suspected malignant ovarian neoplasms (Figure 3). The preoperative serum tumor markers were showed that CA125 was 521.2 (normal $\leq 35$ IU/ml), and CA19-9 was 83.3 (normal $\leq 37$ IU/ml). Her plasma luteinizing hormone, follicle stimulating hormone, estradiol and testosterone were $0.87,4.18, \leq 10$ and 0.37 , respectively. The cytology of the pleural effusion was positive.

Under the working diagnosis of malignant ovarian tumor, the patient underwent an exploratory laparotomy and the lt-ovarian mass had adhered to the small intestine firmly. A massive ascites was also collected. The tumor was extracted after exfoliation from the small intestine. There were no peritoneal implants or metastases to other abdominal organs. The resected tumor size was over $10 \mathrm{~cm}$ in diameter, and the cut surface showed cystic areas with gelatinous material and solid areas of white-yellow (Figure 4). Cytology of the resected tumor suggested a mucus-producing malignant tumor (Figure 5).

The patient had a normal postoperative recovery without any complications. The diagnosis of proliferative BT with borderline mucinous cyst adenocarcinoma of the ovary was established from the histopathologic examination. Microscopically, the cysts were lined broad papillae with fibrovascular cores covered by transitional cells resembling low-grade transitional cell carcinoma of the urinary tract, with squamous metaplasia and mu-

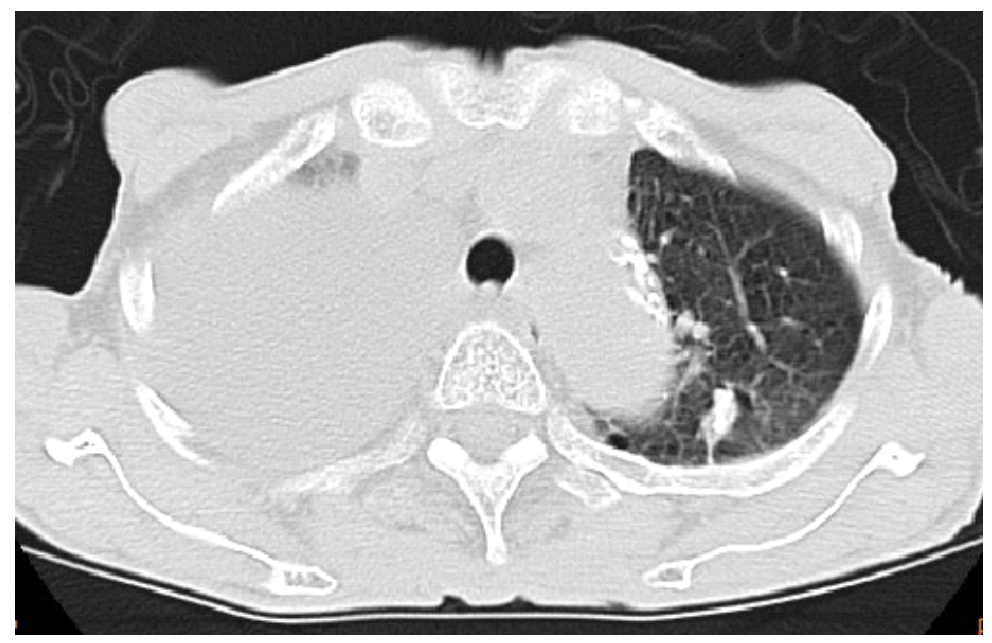

Figure 1. CT examination before inserting of pleural trocar tube showed massive pleural effusion. 


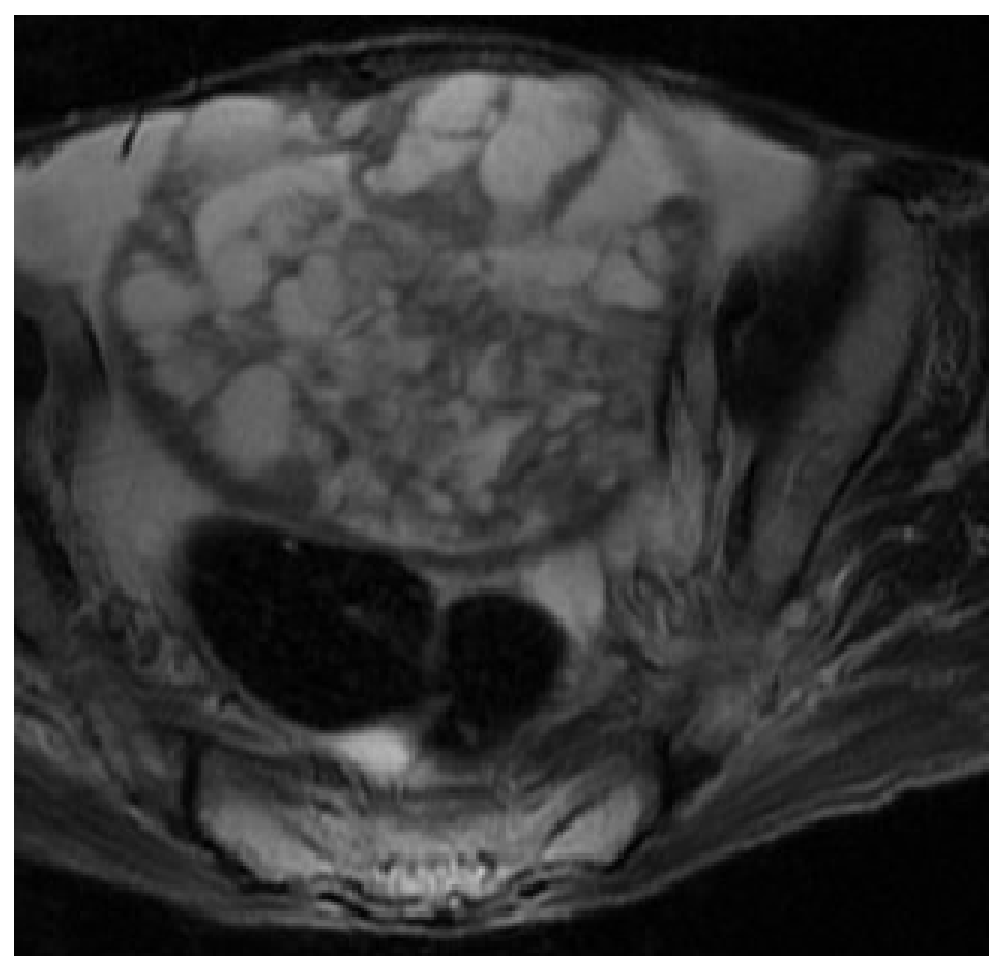

Figure 2. A well-circumscribed solid tumor $(10 \times 8 \mathrm{~cm})$ was detected in the pelvis. Solid and cystic areas were present, suggesting producing high-intensity signals on T2-weighted MRI.

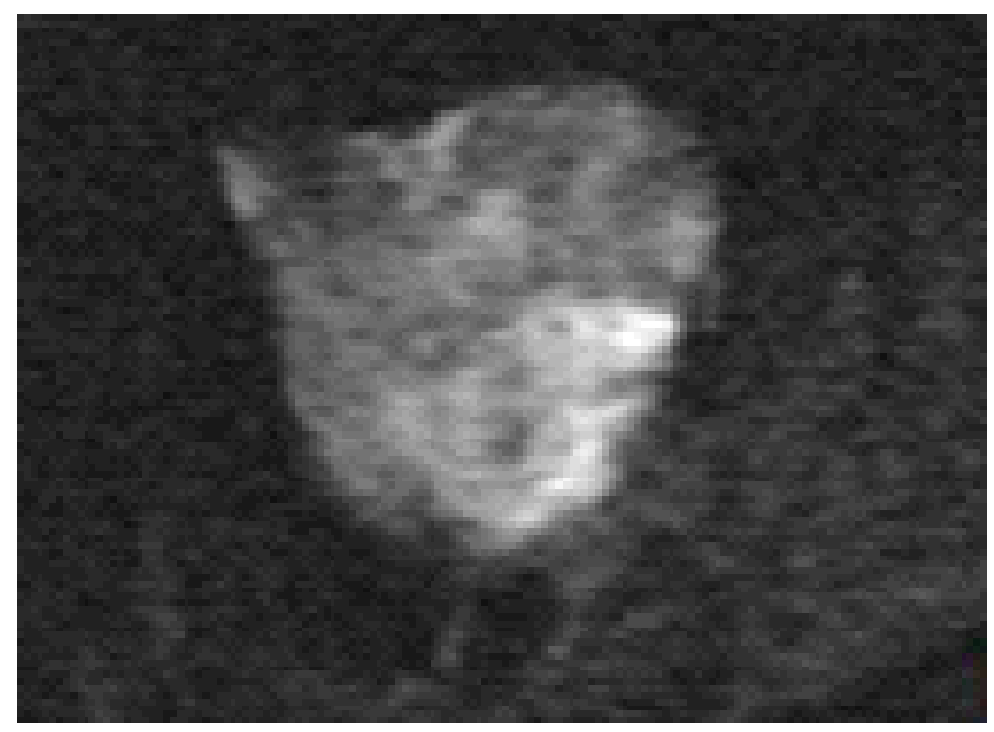

Figure 3. Diffusion-weighted MRI suggested a malignant ovarian neoplasm.

cus-producing part (Figure 6(a)). No invasion was demonstrated. The immunohistopathological examination for the tumor was positive for CK 7 (Figure 6(b)) and negative for CK 20 (Figure 6(c)), suggesting the tumor arising from transitional cells, not from mucus-producing tumor. Based on these findings, the tumor was diagnosed as a proliferative BT with borderline mucinous cystadenocarcinoma, metastasizing to the pleura in FIGO stage IV.

The thoracic trocar tube was removed on post-operative day 7, because discharge of pleural effusion disappeared. She underwent four courses of chemotherapies with paclitaxel $\left(135 \mathrm{mg} / \mathrm{m}^{2}\right)$ and carboplatin (350 


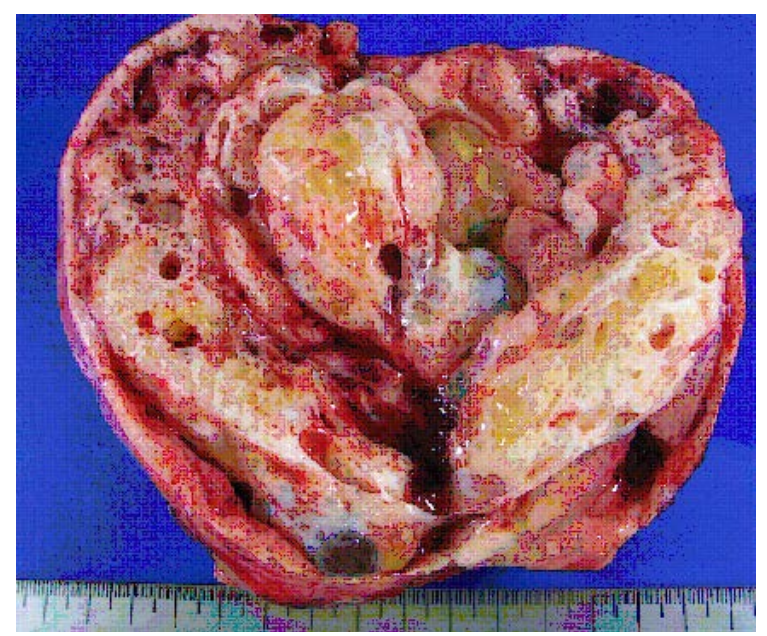

Figure 4. The cut-surface of the resected ovarian tumor was combined with solid and cystic parts. The cystic areas were filled with mucinous fluid and gelatinous material.

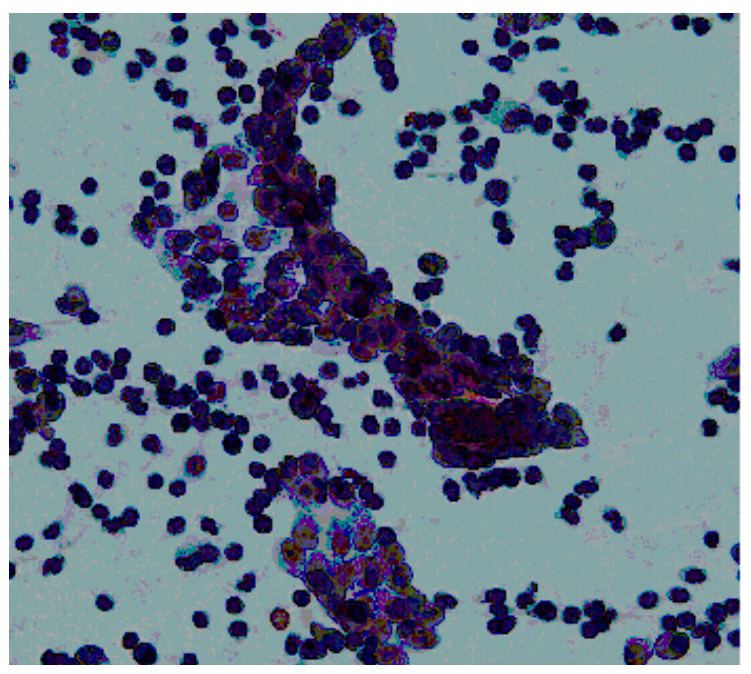

Figure 5. Cytology of the resected tumor suggested a mucin-producing borderline malignant tumor (Papanicolaou stain, original magnification: $\times 400$ ).

mg/body, AUC 5), accompanied in malignant BT cases [7]. The patient showed no signs of recurrence 16 months after the surgery.

\section{Discussion}

Ovarian BTs are rare adenofibromas that account for $1 \%-2 \%$ of all ovarian neoplasms. It is now generally accepted that BTs derive directly from the epithelium of ovarian cortex or from celomic inclusion cysts, which are formed by invaginations of the ovarian celomic epithelium [6] [8] [9]. Histologically, benign BTs have solid or microcystic epithelial cell nests surrounded by dense fibrous stroma. Borderline BTs resemble low-grade transitional carcinoma without stromal invasion, whereas malignant BTs resemble malignant invasive transitional carcinoma with stromal invasion. There is less intervening fibrous stroma in borderline and malignant BTs than in benign BTs [4].

A BT is a rare adenofibroma of the ovary; the epithelial component consists of transitional cells similar to those observed in the urothelium. The most frequent histological subtypes are serous and mucinous lesions [2] [10]. In the present case, massive pleural effusion might be due to both pseudo-Meigs' syndrome and metastasis 


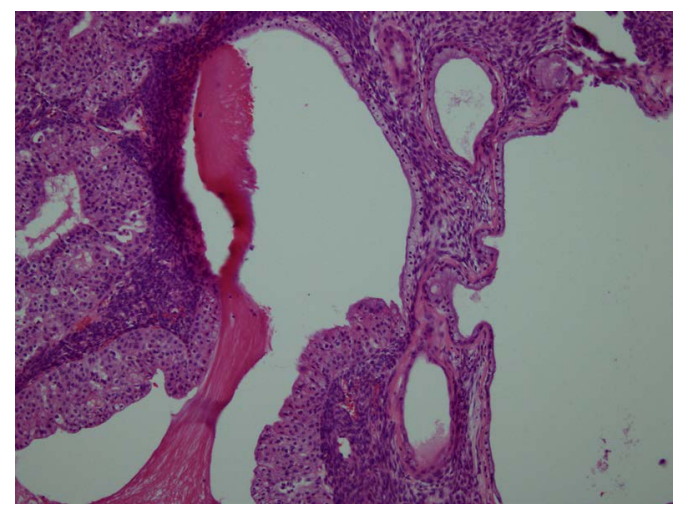

(a)

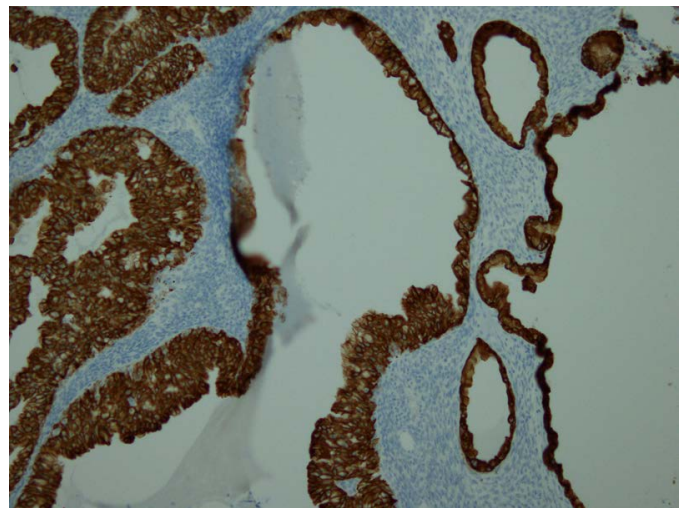

(b)

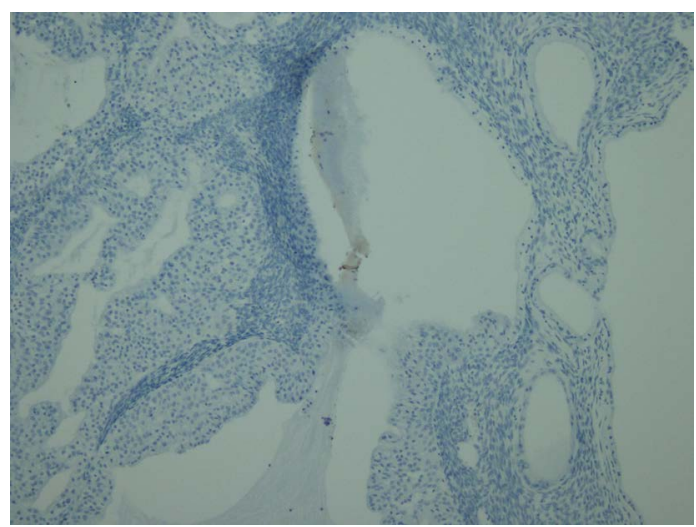

(c)

Figure 6. Histopathology and immunohistochemistry of the tumor. (a) A transitional area of a proliferative BT and mucinous tumor. In the left area, epithelium is thick, pluristratified, with urothelium-like cells but without atypia and absence of stromal invasion. In the right area, monolayer epithelium was lining. Other areas of mucinous part showed mild cellular atypia. (Hematoxylin-eosin stain, original magnification: $\times 200$ ). (b) Both of proliferative BT and mucinous tumor were positive for CK 7. (CK 7 immunohistochemistry, original magnification: $\times 200$ ) (c) Neither of proliferative BT nor mucinous tumor was negative for CK 20. (CK 20 immunohistochemistry, original magnification: $\times 200$ ). 
from the borderline mucinous cystadenocarcinoma derived from proliferative BT through metaplasia. Immunohistochemical profiles of the borderline mucinous cystadenocarcinoma and proliferative BT were same (positive for CK 7 and negative for CK 20) [11]. In addition, cytological findings of the pleural effusion were similar to those of the imprint cytology for the tumor. In the present case, the patient might not notice any subjective symptoms for a long time, until the ovarian mucinous tumor had metastasized to the pleura due to her senile dementia.

In general, the prognosis of a borderline BT is excellent. It is considered to be a tumor of very low risk for recurrence or metastases even many years after excision. Proliferative BTs presumably have non-aggressive biologic behavior, possibly because treatment involves the complete removal of the tumor. Generally, no therapy in addition to surgery is needed [12]. However, we considered that this case needed chemotherapy, because of the pleural metastasis, in a similar manner to malignant BTs [7].

\section{Competing Interests}

The authors declare that they have no competing interests.

\section{Acknowledgements}

We thank the editor and reviewers for their constructive comments, which helped us to improve the manuscript.

\section{References}

[1] Roth, L.M. and Sternberg, W.H. (1971) Proliferating Brenner Tumors. Cancer, 27, 687-693. http://dx.doi.org/10.1002/1097-0142(197103)27:3<687::AID-CNCR2820270326>3.0.CO;2-C

[2] Miles, P.A. and Norris, H.J. (1972) Proliferative and Malignant Brenner Tumors of the Ovary. Cancer, 30, $174-186$. http://dx.doi.org/10.1002/1097-0142(197207)30:1<174::AID-CNCR2820300125>3.0.CO;2-D

[3] Serov, S.F., Scully, R.E. and Sobin, L. H. (1973) Histological Typing of Ovarian Tumours. WHO, Geneva.

[4] Takahama, J., Ascher, S.M., Hirohashi, S., Takewa, M., Ito, T., Iwasaki, S. and Kichikawa, K. (2004) Borderline Brenner Tumor of the Ovary: MRI Findings. Abdominal Imaging, 29, 528-530. http://dx.doi.org/10.1007/s00261-003-0145-4

[5] Fischerova, D., Zikan, M., Dundr, P. and Cibula, D. (2012) Diagnosis, Treatment, and Follow-Up of Borderline Ovarian Tumors. The Oncologist, 17, 1515-1533. http://dx.doi.org/10.1634/theoncologist.2012-0139

[6] Shevchuk, M.M., Fenoglio, C.M. and Richart, R.M. (1980) Histogenesis of Brenner Tumors, II: Histochemistry and CEA. Cancer, 46, 2617-2622. http://dx.doi.org/10.1002/1097-0142(19801215)46:12<2617::AID-CNCR2820461214>3.0.CO;2-M

[7] Gezginc, K., Karatayli, R., Yazici, F., Acar, A., Celik, C., Capar, M. and Tavli, L. (2012) Malignant Brenner Tumor of the Ovary: Analysis of 13 Cases. International Journal of Clinical Oncology, 17, 324-329. http://dx.doi.org/10.1007/s10147-011-0290-7

[8] Arey, L.B. (1961) The Origin and Form of the Brenner Tumor. American Journal of Obstetrics and Gynecolog, 81, 743-751.

[9] Hermanns, B., Faridi, A., Rath, W., Fuzesi, L. and Schroder, W. (2000) Differential Diagnosis, Prognostic Factors, and Clinical Treatment of Proliferative Brenner Tumor of the Ovary. Ultrastructural Pathology, 24, 191-196. http://dx.doi.org/10.1080/01913120050132930

[10] Uzan, C., Dufeu-Lefebvre, M., Fauvet, R., Gouy, S., Duvillard, P., Darai, E. and Morice, P. (2012) Management and Prognosis of Borderline Ovarian Brenner Tumors. International Journal of Gynecological Cancer, 22, 1332-1336. http://dx.doi.org/10.1097/IGC.0b013e318267db2f

[11] Kondi-Pafiti, A., Kairi-Vassilatou, E., Iavazzo, C., Vouza, E., Mavrigiannaki, P., Kleanthis, C., Vlahodimitropoulos, D. and Liapis, A. (2012) Clinicopathological Features and Immunoprofile of 30 Cases of Brenner Ovarian Tumors. Archives of Gynecology and Obstetrics, 285, 1699-1702. http://dx.doi.org/10.1007/s00404-011-2182-5

[12] Arnogiannaki, N., Grigoriadis, C., Zygouris, D., Terzakis, E., Sebastiadou, M. and Tserkezoglou, A. (2011) Proliferative Brenner Tumor of the Ovary. Clinicopathological Study of Two Cases and Review of the Literature. European Journal of Gynaecological Oncology, 32, 576-578. 